\title{
Synthesis and Characterization of Novel Arylene Cyanate Resins
}

\author{
Hiroyuki Sato, Yuta Nabae, Teruaki Hayakawa and Masa-aki Kakimoto* \\ Department of Organic and Polymeric Materials, Tokyo Institute of Technology \\ 2-12-1 S8-26, Ookayama, Meguro-ku, Tokyo 152-8552, Japan
}

Keywords : cyanate ester, thermosetting resin, fully aromatic structure, eutectic

\section{Introduction}

Wide bandgap materials such as silicon carbide are quite attracting for power semiconductor modules. Since such modules require quite high operating temperature at around $250^{\circ} \mathrm{C}$, the molding materials also require extremely high thermal stability as well as good processability. Conventional epoxy resins typically survive only below $150^{\circ} \mathrm{C}$; therefore, the development of novel thermosetting resins is required.

As cyanate ester (CE) resin is a thermosetting resin witch has high thermal stability, it could be a promising material for the molding material of power semiconductors [1-3]. One major problem of $\mathrm{CE}$ resin is, however, low processability at the monomer stage. The processing temperature must be largely lower than the curing temperature considering the fabrication procedure of power semiconductor modules. In this context, it is quite important to develop the CE monomer that has low deformation temperature before curing and good thermal stability after curing.

In the current study, we investigate the mixtures of two different aromatic CE monomers. We expect that the deformation temperature of the monomer mixture becomes lower than that of pure monomer if a eutectic mixture could be prepared [4]. The effect of supercooling is also of interest since aromatic bulky structure might affect the conformational dynamics [5]. Fig. 1 shows the structure of the $\mathrm{CE}$ monomers designed in the current study (CE124, CE12 and CE13). We selected aromatic main chain considering the thermal stability after curing and designed three different but similar structures considering the mutual solubility. Corresponding model compounds (M124, M12 and M13) with methoxy terminal groups were also studied to clarify the deformation and supercooling properties of the mixutures under the condition that is not affected by the curing reaction.

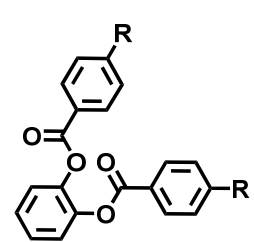

CE12(R:-OCN) $\mathrm{M} 12\left(\mathrm{R}:-\mathrm{OCH}_{3}\right)$

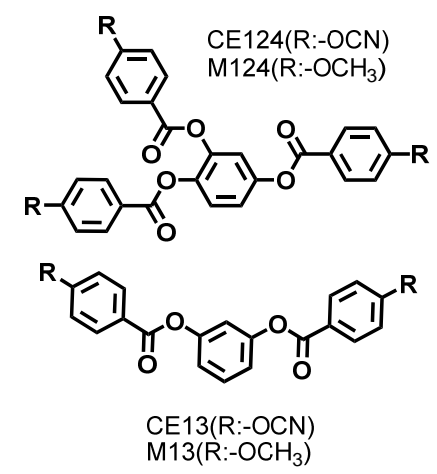

M13(R:- $\left.-\mathrm{OCH}_{3}\right)$
Fig 1. The structures of the $\mathrm{CE}$ monomers and model compounds.

\section{Experimental}

Tetrahydrofuran (THF) was used after distillation from sodium. Triethylamine (TEA), $\mathrm{N}, \mathrm{N}$-dimethylformamide (DMF) and the other chemicals were used as received.

M124, M12 and M13 were synthesized by the routes shown in Scheme 1.

M124: ${ }^{1} \mathrm{H}$ NMR (DMSO-d6, $400 \mathrm{MHz}, \delta$, ppm) $8.11(\mathrm{~d}, 2 \mathrm{H}, \mathrm{Ar}-\mathrm{H}), 7.92$ (dd, 4H, Ar-H), 7.55 (d, 1H, Ar-H), 7.49 (ss, 1H, Ar-H), 7.32 (dd, 1H, Ar-H), 7.14 (d, 2H, Ar-H), 6.99(dd, 4H, Ar-H), $3.87\left(\mathrm{~s}, 3 \mathrm{H},-\mathrm{OCH}_{3}\right), 3.80\left(\mathrm{~s}, 6 \mathrm{H},-\mathrm{OCH}_{3}\right)$; IR $(\mathrm{KBr}$, $\left.\mathrm{cm}^{-1}\right)$ 3076, 3005, 2933, 2821, 1744, 1733, 1581, $1513,1464,1440,1320,1250,1188,1142,1105$, 1063, 1024, 1007, 847, 691, 612, 585.

M12: ${ }^{1} \mathrm{H}$ NMR (DMSO-d6, $\left.400 \mathrm{MHz}, \delta, \mathrm{ppm}\right)$ 7.91 (d, 4H, Ar-H), 7.48-7.39 (m, 4H, Ar-H), 7.00 (d, $4 \mathrm{H}, \mathrm{Ar}-\mathrm{H}), 3.91\left(\mathrm{~s}, 6 \mathrm{H},-\mathrm{OCH}_{3}\right)$; IR $\left(\mathrm{KBr}, \mathrm{cm}^{-1}\right)$ 
$3010,2979,1740,1727,1605,1580,1512,1495$, 1469, 1243, 1171, 1100, 1067, 1021, 851, 760, 692.

M13: ${ }^{1} \mathrm{H}$ NMR (DMSO-d6, $400 \mathrm{MHz}, \delta$, ppm) 8.10 (d, 4H, Ar-H), 7.55(t, 1H, Ar-H), 7.28 (sss, $1 \mathrm{H}$, Ar-H), 7.23(dd, 2H, Ar-H), 7.14 (d, 4H, Ar-H), $3.88\left(\mathrm{~s}, 6 \mathrm{H},-\mathrm{OCH}_{3}\right)$; IR $\left(\mathrm{KBr}, \mathrm{cm}^{-1}\right) 3062,2836$, $1725,1604,1510,1478,1455,1321,1251,1165$, 1130, 1066, 1026, 847, 763.

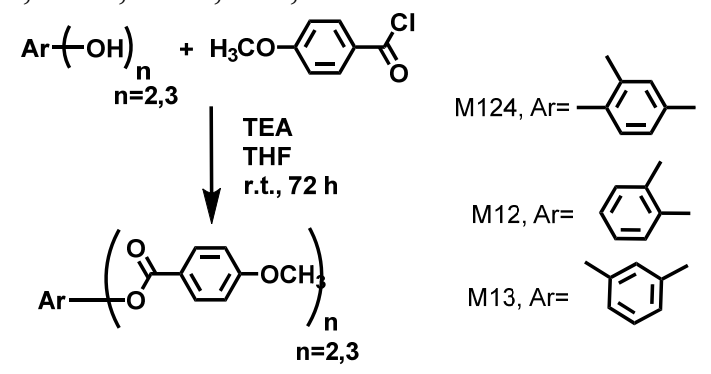

Scheme 1

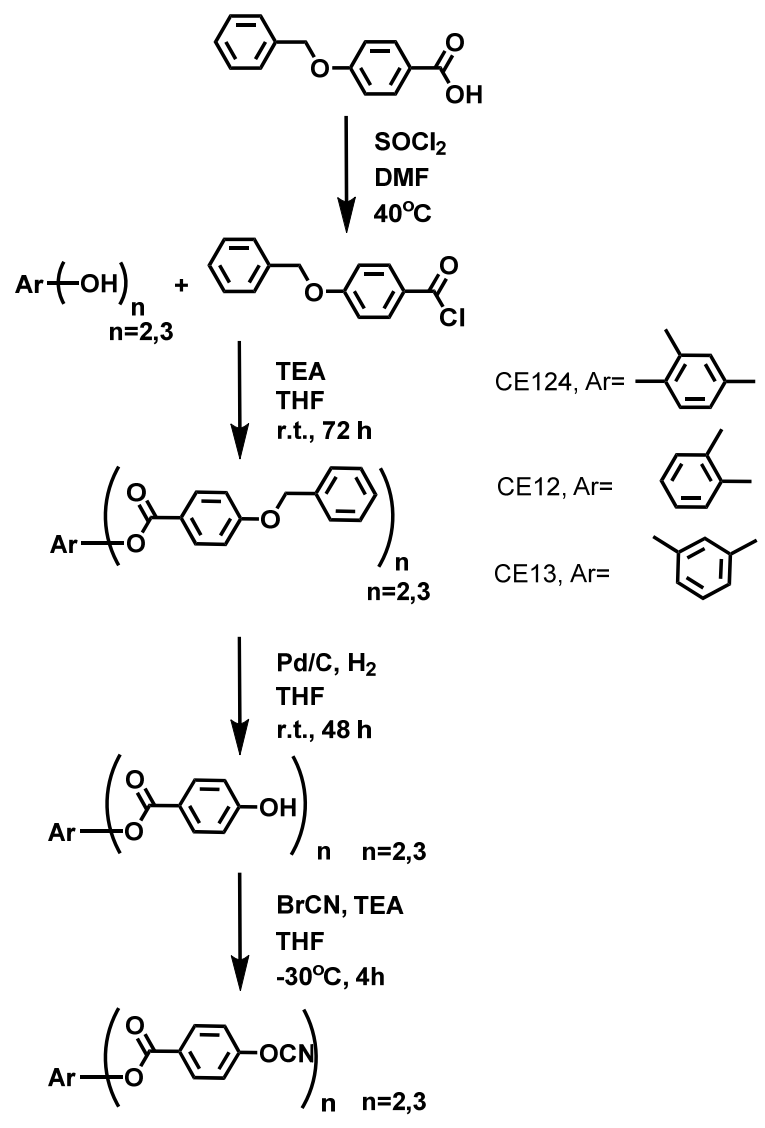

Scheme 2

CE124, CE12 and CE13 were synthesized by the routes shown in Scheme 2.

CE124: ${ }^{1} \mathrm{H}$ NMR (DMSO-d6, $400 \mathrm{MHz}, \delta, \mathrm{ppm}$ ) 8.33 (d, 2H, Ar-H), 8.14(dd, 4H, Ar-H), 7.69(d, 2H, Ar-H), 7.65 (d, 1H, Ar-H), 7.56 (dds, 5H, Ar-H), 7.45(dd, $1 \mathrm{H}, \mathrm{Ar}-\mathrm{H})$; IR(KBr, cm $\left.{ }^{-1}\right) 3107,3068$, 2286, 2258, 2239, 1754, 17401597, 1502, 1416, $1256,1252,1186,1162,1144,1107,1070,1012$,
851, 754.

CE12: ${ }^{1} \mathrm{H}$ NMR (DMSO-d6, $\left.400 \mathrm{MHz}, \delta, \mathrm{ppm}\right)$ 8.14 (d, 4H, Ar-H), 7.56 (d, 4H, Ar-H), 7.57-7.45(m, 4H, Ar-H); IR( $\left.\mathrm{KBr}, \mathrm{cm}^{-1}\right) 3111,3072$, 2287, 2260, 1742, 1599, 1500, 1458, 1418, 1305, $1275,1260,1205,1175,1158,1105,1070,1014$, $845,752$.

CE13: ${ }^{1} \mathrm{H}$ NMR (DMSO-d6, $\left.400 \mathrm{MHz}, \delta, \mathrm{ppm}\right)$ 8.30 (d, 4H, Ar-H), 7.67 (d, 4H, Ar-H), $7.58(\mathrm{t}, 1 \mathrm{H}$, Ar-H), 7.39 (sss, 1H, Ar-H), 7.30 (dd, 2H, Ar-H); $\operatorname{IR}\left(\mathrm{KBr}, \mathrm{cm}^{-1}\right) 3107,3075,2292,2263,1733,1595$, $1499,1479,1417,1308,1273,1212,1164,1143$, $1073,1011,891,851,755$.

The deformation temperatures of the model compounds and CE monomers were determined by thermomechanical analysis (TMA) using SII TMA/SS6000 with a quartz rod probe at $100 \mathrm{mN}$.

Differential scanning calorimetry (DSC) was carried out using SII EXSTAR DSC6000 under $\mathrm{N}_{2}$ flow.

Polarized optical microscopy (POM) was carried out using Olympas BX51 equiped with a heating stage (Mettler Toledo FP90 and FP82HT).

Thermogravimetoric analysis (TGA) was carried out using SII TG/DTA7300 under $\mathrm{N}_{2}$ flow.

FT-IR spectra were obtained with a JASCO 4100 spectrometer by the $\mathrm{KBr}$ pellet method.

\section{Results and discussion}

The model compounds were mixed by dissolving them into dichloromethane and evaporating the solvent. Fig. 2 shows the photo images of the mixtures after the evaporation. Most of samples were collected as white powder, but M124(40)/M12(60), M124(50)/M13(50) and M124(40)/M13(60) kept liquid form. These liquid samples turned into white solid powder within 2 weeks at room temperature; therefore, it is likely that the liquid form appeared by supercooling. The crystallization of the compound was probably inhibited by mixing two different compounds, or the bulky aromatic structure inhibited the conformational relaxation. This may be an instructive phenomenon considering the design of processable monomers although the life of supercooling with the current sample is too short to apply this property to processable cyanate monomers.

The deformation temperatures of thus obtained powder mixtures were evaluated by TMA. Fig 3 shows the deformation temperatures of the mixed model compounds and pure model compounds. The deformation temperature of pure M124, M12 and M13 are 143,126 and $134^{\circ} \mathrm{C}$, respectively. The mixed samples shows lower deformation temperatures. No matter whether the sample shows 
supercooling property, the mixed samples show similar deformation temperatures at around 103 and $108^{\circ} \mathrm{C}$ for the M124/M12 and M124/M13 mixtures, respectively. This tendency is probably because the deformation temperature of the mixed sample reflected the melting point of a eutectic mixture. It is concluded that mixing two compounds would contribute to lower deformation temperature and this information would be useful to design a $\mathrm{CE}$ monomer with a relatively low processing temperature.

\section{(a) $\mathrm{M} 124 / \mathrm{M} 12$}

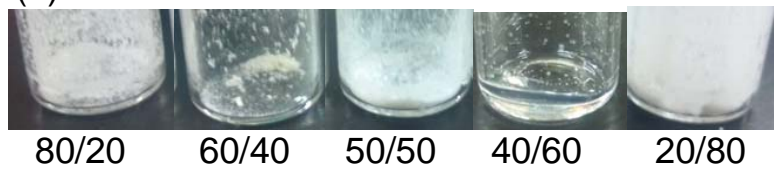

(b) $\mathrm{M} 124 / \mathrm{M} 13$

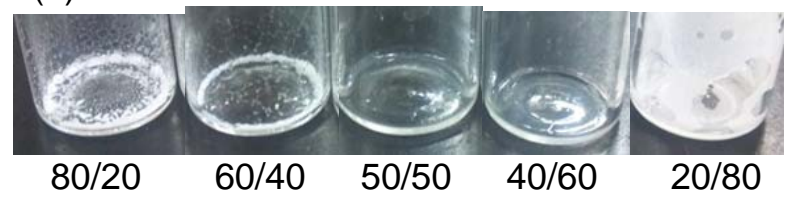

Fig. 2. Photo images of the model mixtures: (a) M124/M12 and (b) M124/M13.

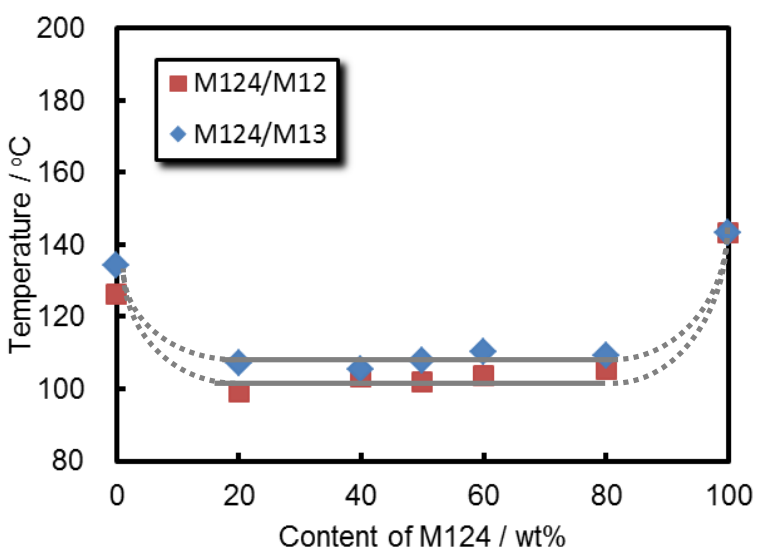

Fig. 3. The deformation temperatures of the M124/M12 and M123/M13 mixtures determined by TMA.

The CE monomers were mixed by dissolving them into dichloromethane and evaporating the solvent. None of the tested samples showed supercooling property in contrast to the model compounds. The deformation temperatures of thus obtained powder mixtures were evaluated by TMA. Fig 4 shows the deformation temperatures of the mixed monomers and pure monomers. The deformation temperature of pure CE124, CE12 and CE13 are 179,120 and $145^{\circ} \mathrm{C}$, respectively. The mixed samples show lower deformation temperatures. They show similar deformation temperatures at around 102 and $136^{\circ} \mathrm{C}$ for the
M124/M12 and M124/M13 mixtures, respectively. This tendency is probably because the deformation temperature of the mixed sample reflected the melting point of a eutectic mixture. It should be noted that the deformation temperature of the CE124/CE12 mixutures is considerably lower than those of pure monomers.

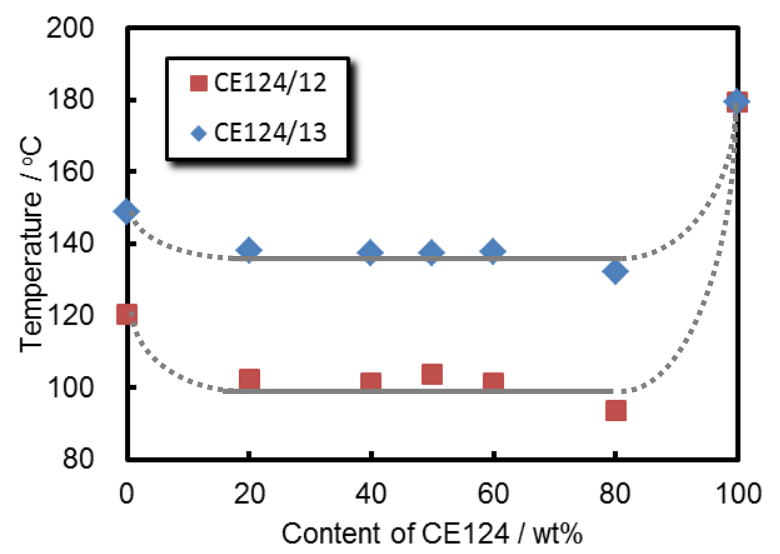

Fig. 4. The deformation temperatures of the CE124/CE12 and CE123/CE13 mixtures determined by TMA.

The deformation and curing behavior of the mixed CE monomers was characterized by DSC and POM. Fig. 5 shows the DSC curves of the CE124/CE12 mixtures. In most samples, relatively sharp endothermic peaks appear at the temperatures which correspond to the deformation temperatures by TMA. Broad exothermic peaks due to the curing reaction appear at around $170-280^{\circ} \mathrm{C}$ with the samples except for pure CE124. In the tested samples, the CE124(50)/CE12(50), CE124(40)/CE12(60) and CE124(20)/CE12(80) mixtures are the most promising considering the gap between the deformation and curing temperatures. Fig. 6 shows the POM images of the CE124(40)/CE12(60) mixture. The sample kept solid state at $120^{\circ} \mathrm{C}$, and partially melted at $148^{\circ} \mathrm{C}$. The sample seems to be a mixture of eutectic melt and unmelted crystals. The optical texture disappeared at $170^{\circ} \mathrm{C}$, suggesting all of sample had melted.

The CE monomer mixtures were cured by the following manner. A sample was placed on an aluminum pan and heated up to $200^{\circ} \mathrm{C}$ under evacuation. And then $\mathrm{N}_{2}$ gas was introduced and the temperature was kept at $280^{\circ} \mathrm{C}$ for $4 \mathrm{~h}$. Fig. 7 shows the FT-IR spectra of the CE124(40)/CE12(60) mixture before and after the curing procedure. The peaks at around $2240 \mathrm{~cm}^{-1}$ due to $\mathrm{O}-\mathrm{C} \equiv \mathrm{N}$ groups significantly decreased and new peaks due to triazine rings appeared at 1373 
and $1559 \mathrm{~cm}^{-1}$ after the curing.

The thermal stability of the cured resins was characterized by TGA. Table 1 summarizes the weight loss at $350^{\circ} \mathrm{C}$ and the temperatures at which $5 \%$ weight loss was recorded $\left(T_{5 \mathrm{~d}}\right)$. In all tested samples, the weight loss at $350{ }^{\circ} \mathrm{C}$ is below 2 wt $\%$ and $T_{5 d}$ is at around $400^{\circ} \mathrm{C}$. It could be concluded that the $\mathrm{CE}$ resins studied in this work have quite promising thermal stability considering the application for the molding materials.

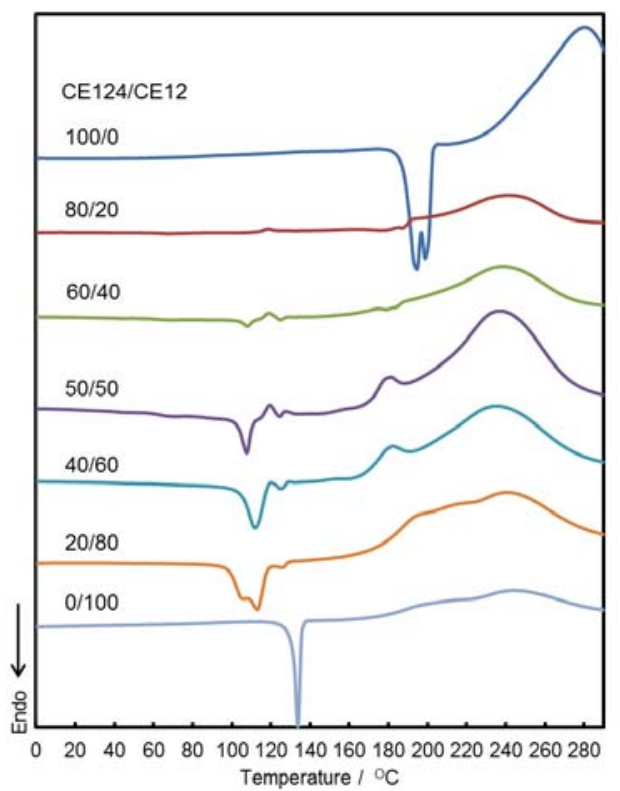

Fig. 5. DSC curves of the CE124/CE12 mixtures under heating.

(a) $120^{\circ} \mathrm{C}$

(b) $148{ }^{\circ} \mathrm{C}$
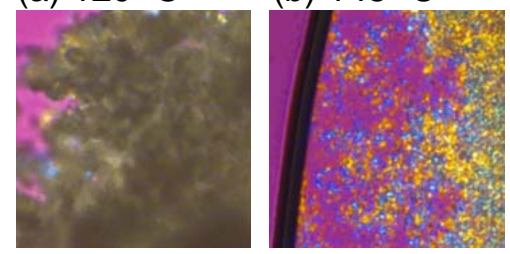

(c) $170{ }^{\circ} \mathrm{C}$

Fig. 6. POM images of CE124(40)/CE12(60) at (a) 120, (b) 148 and (c) $170^{\circ} \mathrm{C}$.

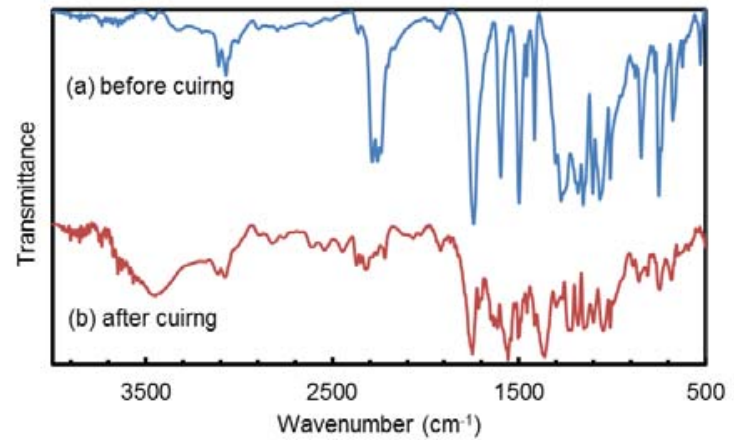

Fig. 7. FT-IR spectra of CE124(40)/CE12(60) (a) before and (b) after curing.
Table 1 Thermal stability characterized by TGA

\begin{tabular}{lcl}
\hline Sample & $\begin{array}{c}\text { Weight loss at } \\
350{ }^{\circ} \mathrm{C}(\%)\end{array}$ & $\begin{array}{l}T_{5 d} \\
\left({ }^{\circ} \mathrm{C}\right)\end{array}$ \\
\hline CE124 & 0.41 & 418.5 \\
CE12 & 2.86 & 375.8 \\
CE13 & 1.23 & 405.0 \\
\hline CE124/CE12 & & \\
$80 / 20$ & 1.50 & 405.0 \\
$60 / 40$ & 1.60 & 399.3 \\
$50 / 50$ & 1.79 & 394.3 \\
$40 / 60$ & 1.46 & 395.8 \\
$20 / 80$ & 1.41 & 390.4 \\
\hline CE124/CE13 & & \\
$80 / 20$ & 1.57 & 410.8 \\
$60 / 40$ & 1.66 & 410.7 \\
$50 / 50$ & 1.22 & 411.2 \\
$40 / 60$ & 0.78 & 411.2 \\
$20 / 80$ & 0.97 & 409.2 \\
\hline
\end{tabular}

\section{Conclusion}

We have designed and synthesized novel arylene $\mathrm{CE}$ monomers and clarified the effect of mixing two different $\mathrm{CE}$ monomers. The deformation temperature was successfully lowered by mixing two monomers. The most promising combination in the current samples is the CE124/CE12 mixture, which shows the deformation temperature at $102^{\circ}$ $\mathrm{C}$ and the curing temperature at around $170-280^{\circ} \mathrm{C}$. All tested samples in this study show promising thermal stability. Further study will be done to achieve even lower deformation temperature by optimizing the structure and composition of the CE monomers.

\section{References}

1. I. Hamerton, J. N. Hay, Polym. Int., 47 (1998) 463.

2. M. Laskoski, D. D. Dominguez, T. M. Keller, Polymer, 47 (2006) 3727.

3. B. Yameen, H. Duran, A. Best, U. Jonas, M. Steinhart, W. Knoll, Macromol. Chem. Phys., 209 (2008) 1673.

4. G. Rothenberg, A. P. Downie, C. L. Raston, J. L. Scott, J. Am. Chem. Soc., 123 (2001) 8701.

5. P. A. Bonvallet, C. J. Breitkreuz, Y. S. Kim, E. M. Todd, K. Traynor, C. G. Fry, M. D. Ediger, R. J. McMahon, J. Org. Chem., 72 (2007) 10051. 